\title{
The Analysis of Collaboration Needs between Vocational Schools and Industry in Internship Based on the Alignment of Graduates' Competence
}

\author{
Eko Supraptono ${ }^{1}$, Samsudi ${ }^{2}$, I Made Sudana ${ }^{3}$, M Burhan RW ${ }^{4}$ \\ ${ }^{1,2,3,4}$ Graduate School, Faculty of Engineering, Universitas Negeri Semarang, Indonesia \\ ${ }^{1}$ Correspondent email: ekosupraptono@ mail.unnes.ac.id
}

\begin{abstract}
The increasing number of job seekers of vocational school graduates in the last three years is caused by the mismatch between graduates' competencies and the needs of the industry. This study analyzed the collaboration needs of vocational schools and industries in the implementation of internship program covering these following aspects: (1) mapping and alignment of student competencies; (2) monitoring the internship program; and (3) evaluation/ competency test/ certification of the internship results. Data collection was conducted on vocational schools in technology and engineering, business and management, and tourism. The results showed that aspects of collaboration: (1) mapping and alignment of student competencies were categorized as high (really important), but only 56\% can be implemented, and $44 \%$ cannot be implemented; (2) monitoring the implementation of apprenticeship was included in the high category, but only $49.5 \%$ can be implemented, and 50.5\% cannot be implemented; (3) evaluation/ competency testing/ certification results of apprenticeship were included in the high category, but only $37.6 \%$ can be implemented, and $62.4 \%$ cannot be implemented. The three aspects of internship on the collaboration between Vocational Schools and the industries were categorized as really necessary, but only $47.7 \%$ can be implemented, and $52.3 \%$ cannot be implemented.
\end{abstract}

Keywords: the need for vocational collaboration, industrial internship, alignment of graduate competencies.

\section{Introduction}

The problem of mismatch between the competencies of vocational school graduates with the needs of industries is still a major issue in the vocational education. The increasing number of job seekers of vocational school graduates who have not been employed in the last four years is caused by a mismatch between vocational school graduates' competencies and the needs of industries. The last four years data on the number of vocational school graduates who have not been employed are increasing. Accumulatively, this figure becomes the biggest contributor to the unemployment rate (BPS, 2016).

One of the efforts to improve the link and match between the competences of students with the needs of the industry can be achieved through the optimization of the internship program. The internship program has not been optimally used by vocational schools in terms of administration of activities, competence trained for students. In terms of administrative activities, many vocational schools, especially the private sectors, do not have good administration. Students are often assigned to search for industries on their own, the school has weak monitoring of the internship, and less accountable certification. From the aspect of competency, there is almost no competency/ expertise mapping that needs to be agreed in advance between vocational schools with industries before the students join the industrial internship.

These issues need to be resolved immediately through the revitalization of the internship program to optimize the process and results of the internship program. The revitalization was conducted through the development of a synergistic collaboration model between vocational schools and industries in the implementation of internship program based on the suitability of graduate competencies. This collaboration does not only optimize the administrative aspects of internship, but also aligns the competency of the graduates through mapping and content agreements. Therefore, the graduates' competencies are aligned with the needs of the industry.

\section{Methods}

The main objective of this research is to reveal the real conditions in the field regarding the collaboration between vocational schools with industry during the internship program on the basis of the alignment of students' competencies which included: (a) mapping and alignment of competencies; (b) monitoring the 
implementation of the internship program according to mapping and alignment on competencies; (c) the evaluation of the results of the internship according to the mapping and competency standards.

Research and development method was employed in this research. The ten steps of Borg \& Gall (1983:773) were simplified, into three major steps, namely: (1) the preliminary study, (2) development and validation, and (3) tests on several vocational educations in technical and engineering department, business and management, as well as tourism.

This research was conducted in Semarang. The study subjects which were sampled purposively consisted of the vocational schools in the field of engineering and technology, business and management, as well as the tourism sector. Only one vocational school was involved for each field. In each area of expertise in vocational school, one program was involved to be revealed regarding the collaboration between vocational schools and industry during the internship program based on the alignment of graduate competencies. Therefore, the subjects of this study were three competencies. Each of the competency was from tourism, business and management, and technology-engineering.

\section{Results and Discussion}

The correspondents in this research consisted of: 1) the principals; 2) productive skill teachers; 3 ) the instructor at the industry. Specifically, the research subjects which were the focus of this research consisted of tourism, business and management, and technology-engineering programs.

On the mapping and alignment of students' competencies, all respondents consisting of 1) the principals; 2) productive skill teachers; 3 ) the instructor at the industry provided responses to the current condition regarding vocational schools collaboration with industry during the internship program. The analysis revealed that $78 \%$ of respondents stated a Memorandum of Understanding (MoU) for the internship program between vocational schools and industry was achieved. Furthermore, 55\% of respondents stated that the MoU specifically showed the synchronization of the training materials/ competencies that students would master during the internship in industry. In the process prior to the internship, 50\% of respondents stated that they had carried out the synchronization of the training materials/ competencies that students would master during the internship in industry.

Furthermore, $47 \%$ of respondents said the training materials/ competency alignments had been carried out through forums and meetings between vocational schools and industry. $47 \%$ of respondents said that they had carried out the process of training material/ competency alignment between industry and vocational Schools in the internship program. Furthermore, $53 \%$ of respondents stated they had carried out the management of ownership of documents/ data regarding the results of material/ competency alignment for both industry and vocational schools. $66 \%$ of respondents stated they had carried out material/ competency debriefing in accordance with the needs of the industry. Furthermore, $55 \%$ of respondents stated that the students had implemented the activities in accordance with the material / competencies agreed upon with the industry during the internship program.

Concerning monitoring the implementation of the internship program, all respondents consisting of 1 ) the principals; 2) productive skill teachers; 3) the instructor at the industry provided responses to the current condition regarding vocational schools collaboration with industry during the internship program. $54 \%$ of respondents stated that between vocational schools and the industries had arranged an agreement to monitor the implementation of the internship program. 50\% of the respondents stated vocational schools and the industries had arranged an agreement to monitor the implementation of the internship program which included: the schedule of monitoring, and stages of students' mastery on the materials/competency. Furthermore, $60 \%$ of respondents stated that the teachers from vocational schools and instructors from the industry had carried out the internship monitoring. The monitoring carried out by teachers referring to the students' mastery of the material/ competency during the internship program in the industry, $56 \%$ of respondents stated that the monitoring was performed well.

Furthermore, $47 \%$ of respondents stated that during the internship monitoring at the industry, the teachers conducts discussions with the instructor at the industry about the alignment of the material/ competency. Furthermore, $60 \%$ of respondents stated that adjustments were made if there were student activities that were 
not aligned with the materials/ competencies with the industry. 58\% of respondents have implemented adjustments to the conditions according to the results of monitoring. It can be concluded that students could conduct in accordance with the material/ competencies that have been aligned.

Regarding the evaluation/ test of competency/ certification of students' internship results, all respondents consisting of 1) the principals; 2) productive skill teachers; 3 ) the instructor at the industry provided responses to the current condition regarding vocational schools collaboration with industry during the internship program. From the analysis of the responses showed that $41 \%$ of the respondents stated that the vocational schools and the industry had to draw up an agreement for the implementation of the evaluation/ test of competency/ certification of Students' internship results. $39 \%$ of respondents stated that they have conducted the evaluation/ test of competency/ certification of students' internship results covering: the mastery of the training materials/competency, implementation of competency tests, and certification.

Furthermore, $33 \%$ of the respondents stated that they had carried out the evaluation of students' internship results by focusing on one of the training materials / competencies. On the other hand, $41 \%$ of respondents stated they had carried out a comprehensive internship evaluation on the training materials/ competencies. Furthermore, $41 \%$ of respondents stated that they had performed the evaluation of the results of students' internship on the mastery training materials/ competency agreed upon between the vocational schools and industry.

$26 \%$ of respondents stated that they had carried out the evaluation of students' internship results by focusing on one of the training materials/ competencies. $41 \%$ of respondents said that the implementation of the competency test of the students' internship was performed on all competencies of the internship results. Furthermore, $44 \%$ of respondents stated that they had performed the evaluation of the results of students' internship on the mastery training materials/ competency agreed upon between the vocational schools and industry. 30\% of respondents stated that they had performed certification of the results of the students' internship on one of the internship results. $42 \%$ of respondents said that they had performed the certification of the results of students' internship in all fields of the internship results.

On the mapping and alignment of students' competencies, all respondents consisting of 1) the principals; 2) productive skill teachers; 3 ) the instructor at the industry provided responses to the current condition regarding vocational schools collaboration with industry during the internship program. $56 \%$ of the respondents had performed the mapping and alignment of students' competencies during the internship program. However, $44 \%$ of the respondents stated that they have not been able to perform the mapping and the alignment. These results showed that the vocational schools and the industries have established good communication for the management of vocational students' internship in terms of mapping and alignment of the students' competencies.

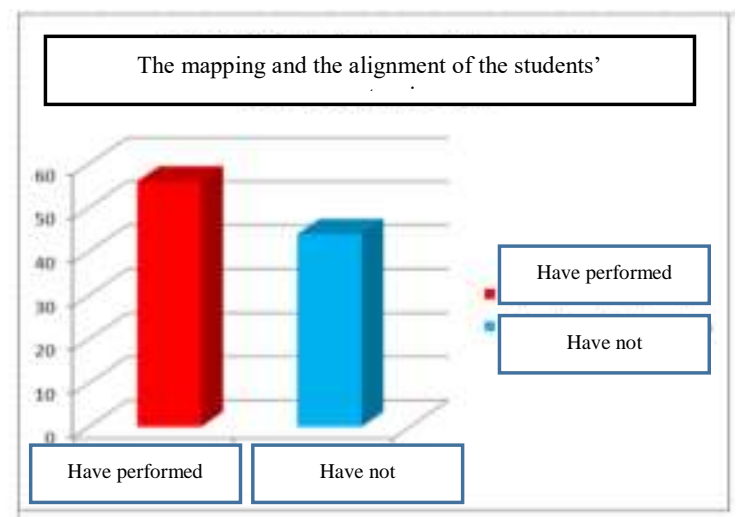

Figure 1. Mapping and Alignment of Students' Competencies

Regarding monitoring the implementation of students' internship, $49.5 \%$ of respondents stated that various monitoring activities could be conducted. However, $50.5 \%$ of monitoring activities related to the implementation of students' internship had not been performed. The internship monitoring has been conducted by both by vocational schools and the industry. However, the level of monitoring was only limited to supervision. It was not specifically investigating the alignment of internship competencies carried out by students in the industry. 


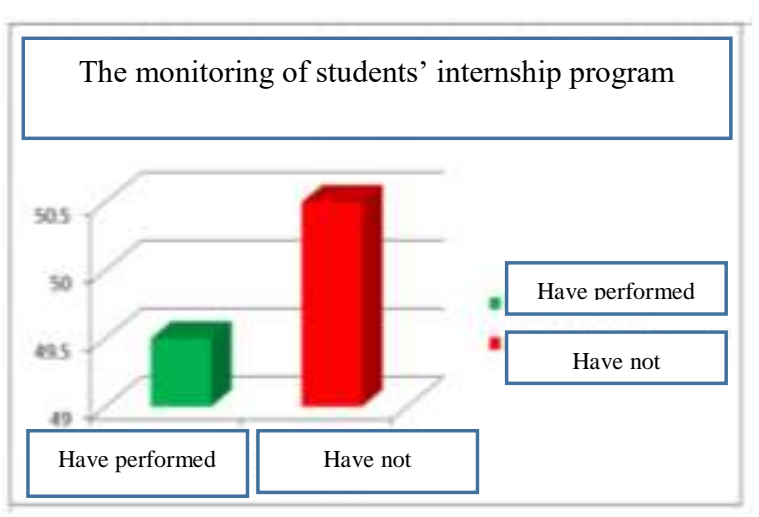

Figure 2. Monitoring the Implementation of Students' Internship

Regarding the evaluation/ competency test/ certification of students' internship results, $37,5 \%$ of the respondents stated that the evaluation of students' internship could be performed and $62.4 \%$ have not been able to carry out a good evaluation of the implementation of students' internship.

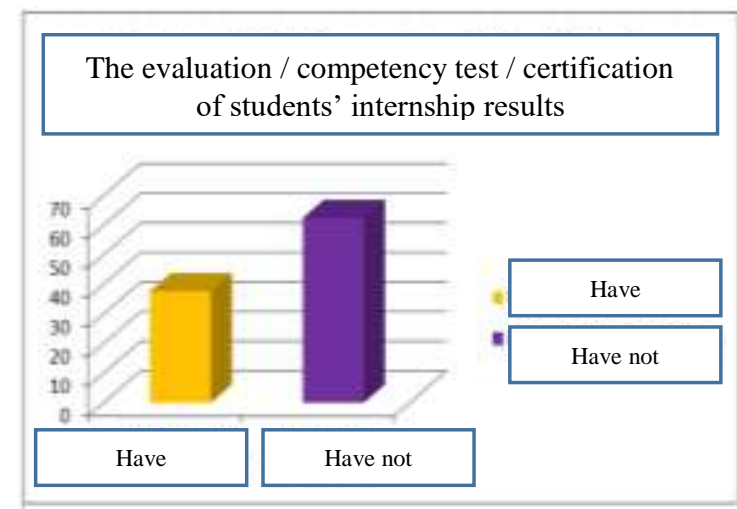

Figure 3. Evaluation / Competency Test / Certification of Students' Internship

\section{Conclusion}

Mapping and alignment of the students' competencies/ skills for the internship based on the industry and vocational schools alignment have been implemented. However, Mapping and alignment of the students' competencies/ skills for the implementation of internship have not been conducted comprehensively. Not all monitoring processes on the internship program have been performed in accordance with mapping and alignment on students' competencies. The monitoring of the implementation of the internship program has been performed generally and partially. It has not yet focused on certain areas of competence. The evaluation/ competency test on the results of the internship program in accordance with the mapping and the alignment of competency between vocational schools and the industries could be performed. However, this evaluation process has not been carried out comprehensively in accordance with the graduates' competencies.

\section{Reference}

The Central Bureau of Statistics. 2016. Data on open unemployment according to graduates of education. Jakarta: update 4-4-2016.

Borg, Walter R. and Gall, Meredith D. 1983. Educational Research: An Introduction. New York and London; Longman.

Fjellstrom, Magnus. 2015. Project-based vocational education and training: opportunities for teacher guidance in a Swedish upper class school. Journal of Vocational Education \& Training. Volume 67 Issue 2. Pages 187-202.

Flynn, Matthew, et.al. 2015. Boundary crossinga theoretical framework for understanding the operational dynamics of industry-school partnerships. Flynn/ Pillay/ Watters. Issue 5. www.tvet-online.asia

Hands, Catherine. 2006.

It's

Who You Know And

What You Know: The Process Of Creating Partnerships Between Schools And Communities. The School Community Journal, Vol. 8, No. 12, pg. 64 -84.

Presidential Instruction No. 9 of 2016 concerning Revitalization of Vocational Schools.

Ministry of Education and Culture. 2016. Revitalization of Vocational Education. Jakarta: 2016.

Decree of the Minister of Education and Culture of the Republic of Indonesia Number 323/ U/ 1997 concerning Implementation of Dual System Education.

Mihaela Gabriela Neacşu, 2015, "A Practical Model for Professional Training at the Workplace". Social and Behavioral Sciences, 204 (1), p. 1184-1191, ISSN: 1877-0428.

Pillay, Hitendra; Watters, Jamnes J; Hoff, Lutz \& Flynn, Matthew. 2014. Dimensions of effectiveness and efficiency: a case study on industry-school partnerships. Journal of Vocational Education \& Training. Volume 66, 2014 - Issue 4 . Pages 537-553

Syamhanim Ismail a, Mimi Mohaffyza Mohamad a, Norasyikin Omar. 2015. "A 
Comparison of Work-based Learning Models and Implementation in Training Institutions". Social and Behavioral Sciences, 204 (1), p. 282-289, ISSN: 1877-0428

Widodo,Joko; Samsudi; Sunyoto. 2016. Implem entation of Industrial Work Practice
Management at Vocational High School. Engineering International Conference (EIC), 5-6 Oct, .2016, Published by the American Institute of Physics. 